Open Access

\title{
Task engagement: a potential criterion for quality assessment of language learning tasks
}

Zohre Mohamadi

\author{
Correspondence: \\ Zohre.mohamadi@kiau.ac.ir; \\ Zohreh.zenooz@gmail.com \\ English Teaching Department, Karaj \\ Branch, Islamic Azad University, \\ Karaj, Iran
}

\begin{abstract}
Maximizing learning opportunities has long been the focus of research in teaching English as a foreign language. Besides the degree to which learners are engaged with the linguistic aspects, investigating other potential of the tasks is of prime importance for maximizing learning opportunities. The present research investigates the potential of four different task types (translation, dictogloss, text reconstruction and jigsaw) performed by 80 Iranian English as foreign language (EFL) intermediate students in promoting learner engagement. Learner's movement from limited to elaborate behavioral, affective and cognitive engagement at verbal, paralinguistic and functional levels while performing the tasks was studied using conversation analysis techniques. The conversation and episodes were coded using a predetermined template of coding. The conversation and ANOVA (analysis of variance) results show that as mind goes through transformation, it is indicated in the transformation in dialogic discourse (speech). The results also indicated that although task engagement patterns were the same across all tasks, the tasks have different potential in promoting task engagement. The results imply that besides other task characteristics including task utility, naturalness and essentiality which focus on linguistic aspects, task engagement is an equally important criterion for the quality assessment of the tasks and should be taken into account since it not only creates sustained attention on linguistic aspects but also mediates learning as it engages learners behaviorally, affectively and cognitively. The results also shed lights on the concept of interactional authenticity and how it can be operationalized in practice.
\end{abstract}

Keywords: Intersubjectivity, Quality assessment of tasks, Task engagement, Task types, Interactional and situational authenticity, Dialogic discourse

\section{Introduction}

From among many instructional approaches language teachers implement to maximize learning opportunities and language learners utilize, task-based instruction (TBI) is the most interactive, contextualized and authentic one (Lee, 2016). Communicative tasks in TBI encourage learners to use their linguistic resources to share and convey their intended meaning and information. "TBI holds great potential for fostering self-directed learning by purposefully engaging students in the learning process" (Lee, 2016, p. 83). Task offers learners plenty of opportunities to be engaged in negotiation of meaning and 
language production and at the same time focus on form in interactive sense rather than isolated linguistics resources (Ellis, 2003).

The quality of task was mostly evaluated at three levels: essentiality, naturalness and utility (Ellis, 2003). The task essentiality is if the linguistic element is required for the task accomplishment. Task naturalness retains if the linguistic item naturally occurs as learners perform the tasks and task utility is when the linguistic element is used for effective task accomplishment. If the tasks enjoy the mentioned criteria, they will have the highest potential in engaging learners with learning process. Effectiveness of the tasks can be examined by studying the extent to which they engage learners with the language (Ellis, 2003). Task-based literature is thrived with studies on how task design and implementation manipulate learners' acquiring and learning language.

What is missing and problematic with previous research is that analyzing only how individuals are engaged with language in collaborative tasks masks another important issue which is analyzing how individuals are engaged with the task itself. A task engagement is being engaged with the tasks and accomplishing it without being stopped by inability to convey meaning because of language problems. According to Mozgalina (2015), since sustained engagement with task creates more opportunities to work with language and thus learning, besides the criteria such as task utility, naturalness and essentiality mentioned by Ellis (2003), another criterion should be met for a task to be considered an appropriate one; task engagement. The term "task engagement" highlights the importance of task characteristics in engaging learners in a task because it entails task characteristics such as task difficulty and task stimuli. Uncovering tasks and identifying which task characteristics can engage learners more in the tasks can help learners deeply immersed in learning and make their learning enjoyable and effective (Lee, 2012). Despite the importance of task engagement, few studies have studied it in language learning context (Dembovskaya, 2009; Ma, 2009; Maad, 2012). Furthermore, little attention has been paid to what task engagement is and how it adds to the potential and quality of task. The present research is intended to investigate if different task types have different potential in promoting learner engagement. This research has been organized in the following way. First, it gives a brief overview of recent history on language engagement and task engagement and lays out the theoretical dimension of it. Then, it describes the design, synthesis, characterization and evaluation used. All taken together, as well as the results shed light on how task engagement can help improve the ecology and reality of language learning classes.

\section{Literature review}

A considerable amount of literature has been published on the essentiality, naturalness and utility as the key features adding to the potential of the language learning tasks in engaging leaners with the language (Amirkhiz, Bakar, Samad, Baki, \& Mahmoudi, 2013; Ansarin \& Mohamadi, 2013a, 2013b; Dörnyei \& Kormos, 2000; Foster, 1998; Nakahama, Tyler, \& Lier, 2001; Oliver \& Mackey, 2003; Polio \& Gass, 1998). What is shared and well-addressed among the above mentioned studies is that all these research addressed language engagement by investigating how task design and implementation can affect varying degrees of attention and effort learners put into task 
performance as they are engaged with language. Language engagement is the degree to which learners attend language at the levels of syntax (form), semantics (meaning), phonetics (prosodic features of language) and discourse (recourse to discourse markers for the production of connected speech) to solve and manage communication problems. There is plenty of research investigating which task creates a better medium for learners' noticing and using the target elements as a way for solving their communication problems (Aldosari, 2008; de la Colina \& Mayo, 2007; Storch, 2005; Storch \& Wigglesworth, 2007).

Research on language performance by EFL learners are mostly concerned with the frequency counts of instructed language elements at the levels mentioned above in later language performance of the learners as signs of learning. To better stimulate learners to use the instructed materials, researchers investigate language tasks that have the most potential in engaging learners with language. Over years, language engagement is considered as the most important driving force in research on language learning and teaching (Pellettieri, 2010). Language engagement created by different task types has been considered as a way of directing learners' attention to specific linguistic element through designing learning tasks. Different tasks including dictogloss (a task which is read twice to learners and then requires the learners to write what they remember), text reconstruction (a task in which learners are supposed to reconstruct the task by filling out the missing parts collaboratively) translation task (in translation task students are supposed to translate into and out of language in collaborative way) and jigsaw task (a task for which each learner has a part of information and task accomplishment requires all learners put different pieces of the task information to together to form the whole) were introduced to the field of language teaching and learning.

Paucity of research on task engagement in comparison with language engagement is due to difficulty of defining the term "task engagement". Task engagement is a difficult term to be defined but it can be recognized when it is around or missing. Students' spending much time and effort on tasks and their care about the quality of the work and their tendency to the task for its significance are the signs of student engagement in educational programs (Sandholtz, Ringstaff, \& Dwyer, 1994).

According to Sandholtz et al. (1994), most researchers consider time on task as a measure for student engagement in task. This misbelief led policy makers in educational setting to increase the length of school day since they believe more time in school would lead to higher scores. According to Caulfield (2010), student engagement is seen as a predictor for language learning. Therefore, in order to achieve the objective of all educational setting which is learning, teachers should create such classroom conditions that lead to student engagement.

Meltzer and Hamann (2005) stated that engagement in education literature is defined either as flow or involvement. Csikszentmihalyi (1997) described flow as learners doing tasks in such a way that they lose track of time and place. The flow depends on challenges that a task imposes on learners and their ability level. If there is a balance between the two, the flow occurs. Lutz, Guthrie, and Davis (2006) described engagement as students' involvement with the task and this involvement happens at several dimensions including affective, behavioral, cognitive and social ones.

Affective attributes are related to self-perception of the value of the task and feeling of self-accomplishment when performing the task. Therefore, these attributes will motivate learners to achieve the task. The feeling of self-efficacy is affected by previous 
success in performing the task and perceived difficulty of the task (Hamedani, 2013). Behavioral factors include observable behavior. Regularly attending the class, participating in online and in class discussions, asking questions and class participation are determinants of behavioral engagement on the side of the learners. Cognitive engagement happens with learners' use of cognitive strategies to monitor and manage effective task performance. Social dimension can be observed when learners are socially interactive and collaboratively perform the task (Lee, 2012).

The two terms; motivation and engagement, are used interchangeably by mistake. Although motivation creates task engagement, motivated learners might not engage with tasks due to lack of balance between learners' skill and the task challenge (Wigfield \& Guthrie, 2000). Motivated learners focus on the outcome and the goal whereas engaged learners focus on what is happening. "Motivation will not be maintained if goals or rewards disappear because motivation is a goal-directed behavior and goals and rewards are key elements that sustain learners' voluntary action. However, task engagement can be maintained even when the rewards disappear if the task itself orients and maintains learners' task engagement" (Lee, 2012, p. 11).

Caulfield (2010) stated that engagement is different from motivation. Motivation is a physiological element by which a goal directed activity is achieved. Two subcomponents of motivation are extrinsic motivation which is doing the activity for achieving some external goals and intrinsic motivation in which the primary goal is achieving a personal goal. Both types have facilitative effects on learning, whereas student engagement is narrower in context. This type of engagement is identified by affective, behavioral and cognitive factors according to Caulfield (2010). The study by Russell, Jane, and Mackay (2003) showed that although Australian learners were highly motivated in general, they didn't perform well on tasks because of low task engagement. This suggests the importance of identifying the tasks with highest potential in engaging the learners with task performance.

There are incidences when participants appear to become engaged in the task. Evidence is at the verbal level (increased fluency, more frequent use of the target language, and reduced amounts of procedural talk), paralinguistic level (straighter posture, stronger voice quality) and in fewer nonfunctional behaviors (pencil tapping, head scratching) (Storch, 1998, 2008).

As Platt and Brooks (2002) stated "If in dialogic activity the mind undergoes transformation, then the evidence is to be found in the dialogue itself' (p. 374). Participants' trend of change from pre-engagement position which is characterized by initial silence, long pauses, little speech, uneasy body postures, and more teacher inventions for probing learner talk to task engagement phase which is characterized by silence disappearance, smaller pauses and hesitations, more speech, strategy proposing on the side of students for probing the talk were considered as incidence of their engagement (Platt \& Brooks, 2002).

Therefore, rather than being concerned very much with the engagement at the level of language, teachers should analyze the potential of each task in engaging students in tasks and evaluate how students orient themselves towards task and how intersubjectivity is established as they go through the task. It is no more the matter of the quantity of language elements noticed in task performance rather it is the quality of how these language elements are noticed as the students engaged in the task. This research is intended to investigate the potential of four task types; 
text reconstruction, jigsaw tasks, dictogloss and translation tasks, in engaging Iranian intermediate EFL learners. The following research questions were set to find the answer.

1. What patterns of engagement different task types impose on learners?

2. Is there any statistically significant difference in the potentials of four tasks types; text reconstruction, jigsaw tasks, dictogloss and translation, in promoting learner engagement? What the difference is if any?

\section{Method}

Participants

\section{Students}

To achieve the objectives of this study, 80 intermediate EFL learners were selected through interview assessment based on FSI (Foreign Service Institute) rating scale in a structured interview as they were rated by two raters and then the participants randomly were assigned into four groups. Participants whose scores were one standard deviation above the mean and one standard deviation below the mean were selected as the target participants. Eighty participants made four groups of the study performing four different task types. Twenty students in each group made 10 pairs.

\section{Raters}

Five EFL teachers holding master's degree assisted the researcher in two phases. The first phase is task evaluation and selection. Raters were asked to rate and evaluate the appropriateness of the designed tasks by the researchers according to a checklist (Appendix 1) proposed by Nunan (1989). At the second phase of designing the task, the researcher asked raters to rate task complexity level according to a questionnaire taken from Geldenhuys (2011)' study. The purpose is to ensure that the tasks implemented in the study were with the same complexity level.

Controlling for consistency of task complexity across task types is required so that any difference can be attributed to the performance of participants rather than the preexisting differences in the design of the tasks.

\section{Teachers}

In this study, teachers were given instructions and lesson plans to manage task performances. They were asked to follow the same procedure and have the same amount of observation. They were asked to clarify the points of misunderstanding in the task procedure.

\section{Instrumentation}

\section{Interview}

A structured interview was used for participant selection. The inter-rater reliability index between two trained raters was calculated to be 0.098 which ensures the reliability of decisions made about participant selection.

\section{Task evaluation and selection}

Four task types namely text reconstruction, translation, jigsaw and disctogloss tasks were selected. The reason why these tasks were selected is that studies related to the research on language engagement in task based instruction include these task types. 
Therefore, to make comparability possible between potential of these task types in language engagement reported in the literature and their potential in task engagement investigated in this research, the same tasks were selected to be included in the present study.

The sample tasks (Appendix 2) designed by the researcher were given to five raters for selection and evaluation. Three important criteria were used for selection of the tasks; tasks appropriateness, task complexity and task content consistency. To assure the appropriateness of the tasks for the purpose of the study and to the participants of the study, Nunan (1989)'s checklist was used. Raters' answers to the checklist were used as guidelines for task adaptation, revisions and evaluation. The inter-rater reliability index of 0.89 on raters' rating complexity level of the task according to a questionnaire by Geldenhuys (2011) indicated that raters had agreements on the complexity level of all four tasks types.

The questionnaire had 6 items which were answered by the same five teachers acting now as raters. They were asked to rate the tasks on the basis of their qualitative judgment guided by the checklist (Table 1) mentioned on a 5 level scale ranging from the simplest (1) to the very complex one (5). Although the questionnaire is reported to be reliable in the original study and a valid one since its construct validity was cross validated by a channel of experts, the researcher conducted an inter-rater reliability analysis among five raters using Spearman Brown proficiency formula to ensure reliability of decisions made on the basis of this questionnaire. The inter-rater reliability of 0.85 was taken as an index of reliability in decisions made about task complexity.

To assure task content consistency, a topic familiarity questionnaire was used. The tasks were designed on the basis of the topics learners felt more confident at for speaking. The topic familiarity questionnaire was a questionnaire with 10 items as topics and the participants were supposed to rate the topics as the most familiar to the least familiar on 5 likert scale. Social disorders such as divorce, addiction, gender discrimination, and unemployment rated as the most familiar ones were chosen to be the topics on the basis of which the tasks were designed.

Table 1 Evaluating task complexity

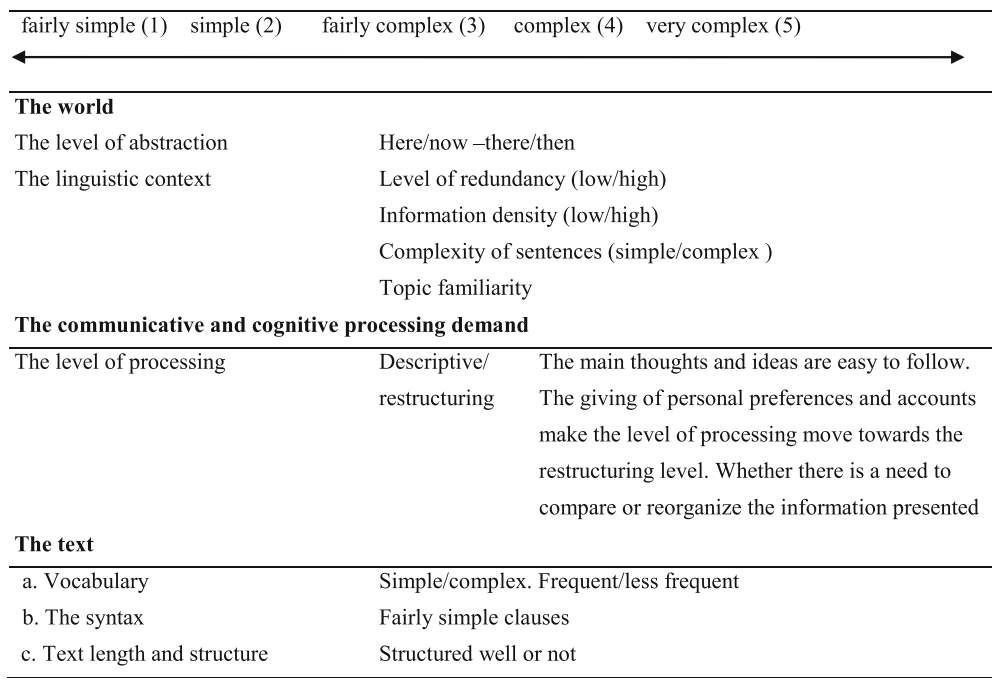

Note: Adapted with some minor modifications from Geldenhuys (2011) 


\section{Procedure}

Having selected the participants and materials, the researcher asked each group to perform a different task (dictogloss, text construction, translation task and jigsaw). Task instructions were given in their L1 to avoid any misunderstanding in how the task should be performed.

The participants' performances across four task types were audio recorded and transcribed for further analysis. The transcriptions were provided to trained raters (the researcher and duty-paid MA graduate). The researcher instructed the rater about what she meant by the construct; task engagement, what the indicators of behavioral, affective and cognitive limited engagement and elaborate engagement are at three levels of verbal, paralinguistic and functional. A transcription protocol which included detailed and individualized guidelines and rules of how to transcribe prepared by the researcher was used. This protocol included a debriefing discussion about the constructs under study; types of limited-engagement and elaborate engagement at verbal, paralinguistic, and functional levels, and task types. Some of the guidelines are using colored highlights in distinguishing the types and levels of engagements, use of common abbreviations in episode analysis and providing a list of them at the end of analysis, providing a justification of why an episode is assigned to a specific type and level of engagement either by commenting in the margin or underlining the features upon which the decision is made.

A predetermined template and manual of coding was used. The template instructed the raters about the possible indicators of limited engagement and elaborate task engagement. An example of each at verbal, paralinguistic and functional levels at the back of the template sheet was included. Raters referred to the examples as guidelines at the back of the template in case they could not decide about the type of the level or the indicators they recognized in the transcriptions. They were supposed to find the indicators in the transcription, highlight them and evaluate what kind of engagement (both in terms of the type and level) they are dealing with as raters to understand what kind of engagement learners undergone. A sample transcription protocol and along with coding template is included in Appendix 3. Each occurrence of the indicators at each type of engagement and at each level was considered as a test score adding to the potential of the tasks. The more the number of the indicators of limited engagement at three levels across four task types, the lower the potential of the tasks is. The more the indicators of elaborate engagement across four task types, the higher the potential and quality of the tasks are.

In order to avoid losing important data specially the nonverbal aspects of the original communication situation such as body language which are especially important at behavioral engagement analysis, the researcher attended the discussion sessions as a nonparticipatory observer to track the nonverbal indicators. Unfortunately the institute did not allow for videotaping the performances which might have maximized the appropriateness and reliability of the decisions made considering the engagement at behavioral level. This is one of the limitations of the study which can be resolved in further studies. Since discussions were sometimes with high pace, to keep up with the pace of conversations, the researcher used a checklist with abbreviations for noting down and tracking the indicators. In this way, the researcher could record behavioral actions taken by the participants such as scratching the head, looking at watch, changing the posture on the seat constantly and etc.

The raters' rating in transpiration analysis and the observers' account of the class analysis were used to answer reliability issues concerning the quality of decisions made about the type and level of engagement in episode analysis. The spearman proficiency 
formula $\left(r \times x=\frac{n \times r}{(n-1) r+1}\right)$ was used to calculate the inter-rater reliability to ensure the reliability of decisions made about the types of engagement and the levels by raters. The correlation between three raters $(0.66)$ made reliability index of 0.85 .

Collected data ranged from 40 to 50 minutes of interaction. To make comparability across the groups possible, all interactions were reduced to 30 minutes. The mean number of interactions across the task types was 381 episodes. The ratio of number of elaborate engagement to pre-engagement equals engagement potential and quality different types of tasks have.

The episodes and conversation analysis through transcription studies of two raters and observations of the researcher were used to answer the first research question. The patterns of engagement were extracted across the four task types. To answer the second research question, each occurrence of verbal, paralinguistic and functional indicators of engagement were treated as test scores adding to the potential of each task in promoting engagement. As the higher test scores show higher amount of an attribute in a person, the more occurrence of the indicators at each level of at elaborate engagement and lower occurrence of those at limited engagement across four tasks indicate higher potential and quality of the tasks. One way ANOVA was used to investigate if there is any statistically significant difference in the types of the tasks and the amount of task engagement at three levels of verbal, affective and cognitive ones.

\section{Data analysis}

\section{Patterns of task engagement across different task types}

The cases of limited and elaborate engagements across four task type performances were studied to investigate how participants moved from the limited engagement to elaborate engagement throughout tasks and to find the patterns of engagement in the tasks to answer the first research question.

\section{Limited and elaborate engagement in dictogloss task}

(1) At the beginning phase of the task performance, there were a lot of L1 uses. But as participants worked through the end, more elaborate task engagement was observed. Example 1

S1: children of divorce became depressed

S2: "Chi" (Meaning "what")

S1: become

S2: are depressed

\section{Example 2}

S1: they cannot meet their social needs

S2: social : "Chi" (Meaning "what")

S1: social needs

S2: no basic needs

Example 3

S1: critical problem

S2: What?

S1: Critical problem

S2: "Tosh bod?" (Meaning was it in the input given?) 
S1: No I added it

S2: ok it is good let' use it

(2) There were a lot of language related episodes but as they moved to the end of the task there was the absence of language related epodes. Rather, there was more engagement at the level of discourse.

Example 1

S1: there were related to each other. Aren't they?

S2: addiction and crime. Yes

S1: addiction and crime can cause pour families

S2: can cause harm effects on poor families

Example 2

S1: children would make the next problem

S2: but I think divorce can cause of this

S1: yes

Example 3

S1: I think it will come the other problem

S2: crime that cause the other problem

S1: (changing the order of the problems)

Example 4

$\mathrm{S} 1$ : the next (rising intonation which functions as an interest to continue)

S2: the next ....

S1: the nest one

$\mathrm{S} 2$ : the nest social issue

S1: we use social issues a lot

S2: ok social problem

(3) There was a case of elaborate engagement at the end of the task since participants provided more personal attitudes.

Example

S1: If he lose his job

S2: and salary

S1: yes I think they have varieties of problems

(4)Long pauses and hesitations and laughs at the beginning of task performance marked lack of task engagement.

Example

S1: it talks about some countries

S2: many countries

S1: (long pauses)

S2: (laughs and looking at the teacher)

\section{Limited and elaborate engagement in text reconstruction task}

(1) The case for the lack of engagement was presenting ideas and not receiving any comments from the partner. The presence of silence is a clue to the lack of engagement.

Example 1

S1: Addiction is the one of the 
S2: is one of the I think is not correct

S1: (silence)

Example2

S1: we don't have high prestigious? What about super?

S2: (silence)

(2) The case for task engagement can be seen as the participants provided their personal attitudes at the finishing phase of the task performance rather than at the beginning phase.

\section{Example}

S1: I believe it is and. Unemployment and poverty

S2: yes exactly

(3) The case of limited engagement can be seen by an appeal for help more at the beginning of task performance.

Example

S1: bad conditions (looking at the teacher to see if the teacher confirms that she is providing the correct form).

S2: bad conditions in people

S1: you can't say bad conditions in people

S2: you can't say bad conditions in people

S1: for example bad conditions for people

(4) The case of lack of engagement can be seen on the side of the participants by exhibiting gestures that show uncertainty in what have been said and no further questioning or clarification requests.

\section{Example}

S1: one social issue is unemployment

S2: rising eyebrows (showing he is not sure about the partners' answer)

S1:(no more elaboration)

S2: (no elaboration request)

(5)Lack of engagement can be seen in cases in which the participants were involved in procedural talk rather than actual performance.

\section{Example}

S1: can we change some vocabularies

S2: no I think we should correct the existing vocabularies

(6) The case of more engagement can be seen at the ending phase of the task as the participants showed gestures signaling they were satisfied with the task.

\section{Example}

S1: crime has

S2: we should change have

S1: gesture (meaning confirmation on the side of the participants rather than silence)

(7) The case for elaborate task engagement can be seen as participants asked for reasons and elaboration on why the partner thought so.

\section{Example}

S1: we can't use seen alone

S2: why

S1: have seen or have been seen

S2: we can use both of them?

S1: yes 


\section{Limited and elaborate engagement in translation task}

(1)Lack of task engagement could be observed at the beginning of task as there were long pauses and hesitations and laughs.

Example

S1: poverty (long pause)

S2: poverty (correcting the pronunciation)

S1: (Laughs and long pauses and looks at the teacher)

S2: (no interference to make the task run)

(2) The case of the elaborate engagement could be seen on the participants' side by expressing their own feeling at the end of the task.

Example 1

S1:less safety

S2: I am not sure

S1: I think it is ok

S2: I like this sentence "the most important problem"

Example 2

S1: I think if we used both it is better

S2: I got confused

S1: ok both men and women

S2: Aha yes

Example 3

S1: experience many problems

S2: it is Farsi. It is word by word

S1: ok let's say have many problems

(3) The case of limited engagement could be seen by an appeal for help either from the teacher or checking some reference books at the beginning of the task.

Example 1

S1: let's check dictionary

S2: Trying to find a dictionary from her bag and looking to the teacher to see if they can use dictionaries

Example 2

S1: what about "sarpanah"

S2: shelter

S1: we can check from dictionary

S2: it is shelter

Example 3

S1: (looking at the teacher and asking excuse me Mam "bikari" means?

S2: unemployment

S1:yes unemployment

S2: yes

Example 4

S1: asking teacher "ostad barovorde kardan chi mishe"? (Meaning what does their unknown word mean?)

S2: satisfied 
S1: yes for needs

S2: ok satisfied

(4) The case of elaborate engagement on the side of the partners could be seen when they coined a word for the words they did not know the English equivalent.

Example

S1: crime is wrong

S2: we need criminal people ok?

S1: criminal people is good

(5) The case for elaborate task engagement could be seen as participants asked for reasons and elaboration on why the partner thought so.

\section{Example}

S1: why feeling?

S2: ok what?

S1: sense

S2: sense of responsibility yes it is better

(6) There was no more reliance on the teacher at the end of the task. The participants provided their own justification rather than asking for help. The justification sometime provided in Persian.

\section{Example}

S1: Next violence

S2: Next no

S1: why? Next violence

S2: "kheyli ziyad estafade shode" (Meaning they have used this word a lot though the task

S1: ok the other

(7)Full engagement could be seen when there is argument between the participants almost like a fight.

\section{Example}

S1: not allow and take their sense of responsibility

S2: use simpler words

S3: no it is ok

S1: but the sentence is incomplete

S2: no it is ok

S1: incomplete

S2: (getting angry and insisting it is ok)

\section{Limited and elaborate engagement in jigsaw task}

(1)Lack of engagement could be seen in cases in which participants were involved in procedural talk rather than actual task at the beginning of the task.

\section{Example 1}

S1: what we should write?

S2: we want to cover all these pictures

S1: yes I start with my picture

S2: ok 


\section{Example 2}

S1: Mohsen I think we can make connection between them

S2: yes

S1: do you want to make the connection or talk separately

(2) The case of the elaborate engagement could be seen on the participants' side as they provide their own feeling near to the end of the task.

Example

S1: I think some of the reasons is game

S2: yes one of the reasons is game especially for boys

(3) The case of limited engagement could be seen by an appeal for help either from the teacher or checking some reference books at the beginning of the task.

\section{Example 1}

S1: "baraye talagh che feli estefade mishe alan yadam nemiyad" $(\bullet . .$. (meaning what is the verb for divorce I cant remember it now)

$\mathrm{T}$ : get

S2: get divorce?

T: yes

S1: ok

\section{Example 2}

S1: children wear "pare" (looking at the teacher for help

S2: torn? (Looking at the teacher for confirmation)

\section{Example 3}

S1: and this unemployment causes the rate of crime to increase. Is it true?

S2: yes

(4)The case of elaborate engagement at the end of the task was seen when the participants provided ideas which were beyond the input provided in the task design at the end of the task.

Example 1

S1: (providing more ideas on the issue of poverty

S2: I think it is enough let's talk about other problems

\section{Example 2}

Participants were really engaged in the task as they provided brilliant ideas about the topics and there was absolutely no tendency to finish writing about each topic in the way that the teacher asked them to do.

(5)No more reliance on the teacher was seen at the end of the task as the participants provided their own justification.

\section{Example 1}

S1: people who have "party" we say in Farsi

S2: what we can say for "party"?

S1 supporters?

S2: yes

(6) The case of lack of engagement is when they look at the teacher to see if their talk on each topic is enough or they were supposed to talk more which was exactly opposite to the cases in which they went beyond the input given and provided more brilliant ideas on their own. 
(7) The case for elaborate task engagement could be seen as participants asked for reasons and elaboration on why the partner thought so.

Example

S1: they get divorce because his addiction makes continuation of life difficult

S2: and also she should underestimate her husband trying to keep her head above water

S3: she shouldn't underestimate

The results of conversation analysis through moment to moment construction of interactions are tabulated in Table 2 which indicates how participants were engaged with the task as they moved from the beginning phases of the task performance to the end. The analysis of the conversations across tasks showed that participants went through the same patterns of engagement as they tried to establish their joint ownership of the tasks and intersubjectivity.

One sign of pre-engagement or limited engagement on the side of participants across tasks was their attention to form at the beginning of task. There were the cases of engagement at the level of form. But, as they moved towards the end of the task their correction at syntax level was reduced and they maneuvered more on the textual and interpersonal issues at discourse level.

Another sign of pre-engagement was an appeal for help either from the teacher or from dictionary for the words participants could not remember. This sign of preengagement was disappeared as participants were engaged in the tasks and tried to coin words or explain the words they didn't remember.

The third sign for the limited engagement on participants' side was recourse to their native language, Persian, to resolve the challenges they met but as they moved through the task and engaged with it, the frequency of recourse to Persian became less which can be interpreted as a sign of task engagement.

The fourth sign is the presence of non-verbal reactions such as long pauses, silence, hesitations and laughs that showed frustrations and gestures that showed uncertainty at

Table 2 The trend of change in task engagement across four task types

\begin{tabular}{|c|c|}
\hline Limited engagement & Elaborate engagement \\
\hline \multicolumn{2}{|l|}{ Verbal Level } \\
\hline $\begin{array}{l}\text { 1. L1 use } \\
\text { 2. Engagmnet at the level of syntax } \\
\text { 3. Procedural talk } \\
\text { 4. Mere compliance with the requirements of } \\
\text { the task } \\
\text { 5. Appeal for help from reference books or teacher }\end{array}$ & $\begin{array}{l}\text { 1. No L1 use } \\
\text { 2. Engagement at the level of discourse } \\
\text { 3. Actual talk } \\
\text { 4. No tendency to finish the task and provide } \\
\text { information beyond the requirements of the task } \\
\text { 5. coining words and the use of strategic } \\
\text { competence }\end{array}$ \\
\hline \multicolumn{2}{|l|}{ Paralinguistic Level } \\
\hline 1. Presence of silence & 1. Absence of silence \\
\hline 2. Long pauses, hesitations and laughs & 2. More fluent language use \\
\hline \multicolumn{2}{|l|}{ Functional Level } \\
\hline $\begin{array}{l}\text { 1. Appeal for help from the teacher } \\
\text { 2. Gestures showing uncertainty }\end{array}$ & $\begin{array}{l}\text { 2. No more reliance on the teacher and students } \\
\text { provide their own justification even in } L 1 \\
\text { 2. Gestures showing satisfaction with task } \\
\text { performance } \\
\text { 3. Arguments between the partners almost like } \\
\text { a fight }\end{array}$ \\
\hline
\end{tabular}


the beginning of task. Towards the end of the task, participants showed more verbal reactions and even they provided some non-verbal gestures, the gestures were used to show confirmation and certainty and being in line with the other interlocutors.

The fifth sign of limited engagement was participants looking at the teacher to see if the ideas they had presented were enough or they were required to go further. The counterpart was participants' interest in continuing the task and providing brilliant extra ideas beyond requirements for fulfilling tasks.

The next sign of limited engagement was participants' talk over procedures they were required to perform the task. At the beginning of the task, there were more procedural talk by which participants tried to orient themselves towards the task whereas at the end of the tasks participants not only presented extra ideas beyond the ideas included in the task but also provided justification, reasons and explanations about why they thought so.

The last point about the pre-engagement and engagement was whether participants provided any case of personal feeling. At the beginning of the task, participants didn't provide their own personal feeling, neither about the content of the tasks nor about the syntactic, intonation and discourse devices. But, towards the end of the task they showed their personal feeling by saying if they liked a special grammatical structure or if they always had problems in using a special kind of syntactic device or whether they wanted to provide special kind of organization at discourse level such as showing cause and effect or putting an order to the ideas in the way they liked.

\section{Potential of different task types in promoting task engagement}

In order to investigate if the types of tasks make a significant difference in the amount of task engagement at verbal, paralinguistic and functional levels, analysis of variance (ANOVA) were used. Each occurrence of verbal, paralinguistic and functional indicators at elaborate engagement was treated as a test score adding to the potentials of the tasks in promoting engagement. As the higher test scores show higher amount of an attribute in a person, the more occurrence of the indicators at each level of at elaborate engagement and lower occurrence of those at limited engagement across four tasks indicate higher potential and quality of the tasks. The results of the analysis are indicated in Tables 3 and 4.

Table 3 shows task engagement across four task types; text reconstruction $(M=133)$, translation task $(M=62)$, dictogloss $(M=75)$, jigsaw tasks $(M=110)$. Mean comparison of engagement across tasks is indicated in Table 4.

Table 3 Descriptive statistics on task engagement

\begin{tabular}{llrrrrr}
\hline & Number & Mean & Std. deviation & Std. error & \multicolumn{2}{c}{ 95\% confidence interval for mean } \\
\cline { 7 - 7 } & & & & & Lower bound & Upper bound \\
\hline Text reconstruction & 10 & 133.90 & 22.63 & 7.15 & 117.70 & 150.09 \\
Translation & 10 & 62.10 & 17.01 & 5.38 & 49.92 & 74.27 \\
Dictogloss & 10 & 75.00 & 10.33 & 3.26 & 67.60 & 82.39 \\
Jigsaw & 10 & 110.00 & 38.88 & 12.24 & 82.18 & 137.81 \\
Total & 40 & 95.20 & 37.20 & 5.88 & 83.35 & 107.14 \\
\hline
\end{tabular}


Table 4 Mean comparison of task engagement across the task types

\begin{tabular}{lcllll}
\hline & Sum of squares & df & Mean square & F & Sig. \\
\hline Between Groups & 32203.700 & 3 & 10734.567 & 17.738 & .000 \\
Within Groups & 21785.800 & 36 & 605.161 & & \\
Total & 53989.500 & 39 & & & \\
\hline
\end{tabular}

As Table 4 shows, the sig level (0.000) of ANOVA test is less than the research confidence interval (0.05) which means that there is a statistically significant difference in the potentials of the tasks; text reconstruction, translation, jigsaw and dictogloss $(p=0.000<0.05)$. To investigate which task promoted more engagement, Table 3 is recalled. As the table shows text reconstruction has the highest potential and translation has the least potential in promoting learner engagement. The results are also indicated in Fig. 1.

\section{Results and discussion}

Having analyzed the patterns of engagement, the researcher concludes that learners go through the same pattern in performing tasks. Therefore, as far as the differences in patterns of engagement across different task types is concerned, all four task types in this study engaged learners with the task to the same extent. The reason is probably these tasks have certain characteristics that promote positive learning environment, learner autonomy and collaboration; the characteristics of the most engaging tasks according to Kamil et al. (2008).

Learners' mere compliance with language at surface levels such as attending form was changed as they spent more time with the task. Through the entire task performances except

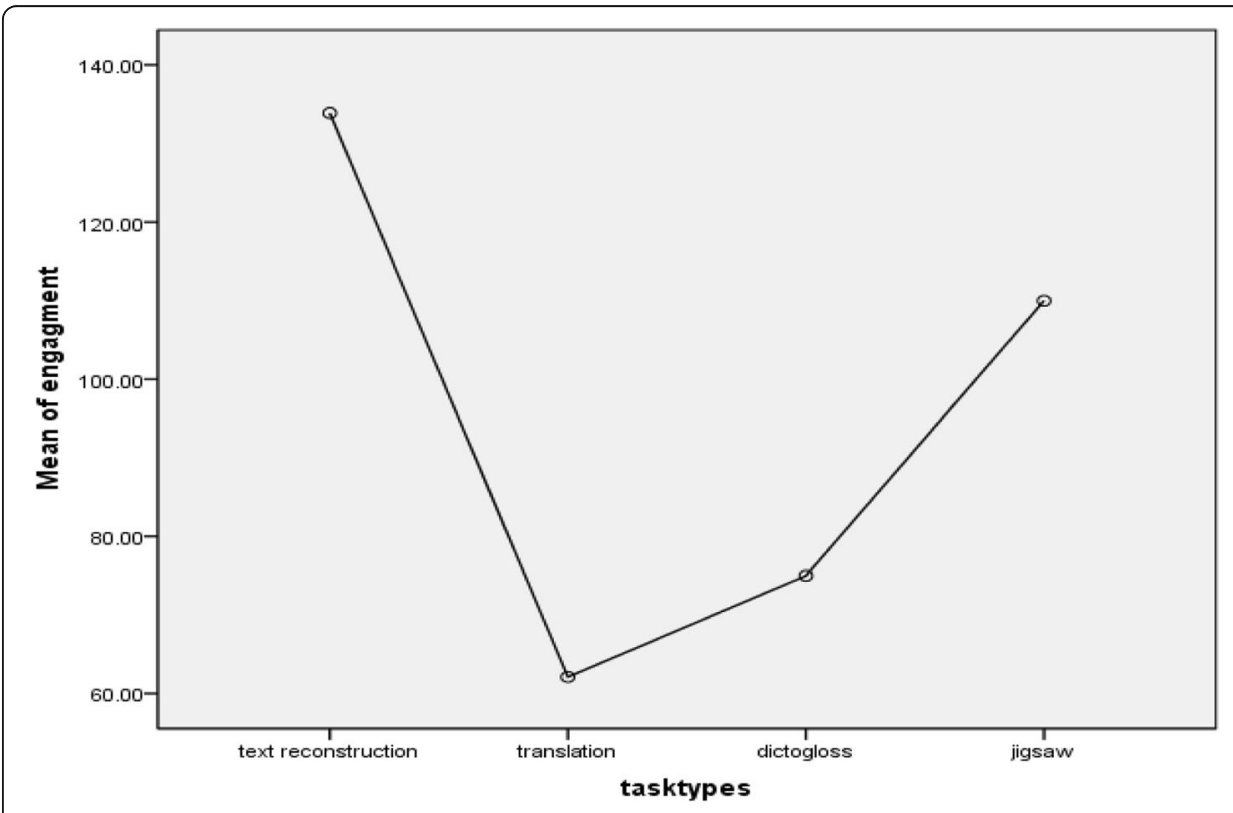

Fig. 1 Mean comparison of task engagement across the task types 
for the beginning phase, learners used more discursive devices and conversation management techniques such as cohesive devices and clarification request to repair their negotiation. Moreover, learners' procedural talk was reduced and they talked more about the content at later stages of task performance. At the beginning stages, learners had more intermental processing since they referred to the teacher or other assistance to communicate what they mean whereas at the later stages of task performance participants engaged in more intramental processing which means they did the things they couldn't do without assistance at the beginning of task performance with more ease and confidence individually at later stages of task performances.

Besides, learners' elaborate engagement and not intending to finish the task at later stages of task performance as a result of interest and engagement indicate that learners establish what Ellis (2003) advocates; contingency. Contingency is making connected speech in dialogic discourse which is a general characteristic of scaffolding. Task engagement can also foster Self-regulated Learning (SRL). According to Paris and Paris (2001), because SRL involves different aspects of learning, it is examined from the standpoint of various theoretical perspectives including Piaget's constructivist theory, Vygotsky's sociocultural theory, social learning theories, and information processing theories. SRL is a mixture of knowledge accompanied by motivation to pursue the goals and supported in the relevant environment that helps students to become autonomous (Paris \& Paris, 2001).

The findings show how the task engagement is mediated by early language engagement. The participants messily engaged with the task. At some moments, some members of the group appeared to be dealing with other matters and they appeared to be working together sometimes and not at other times. There seems to be varying degrees of engagement and involvement with the task. This shows quality of different tasks as they engage students not only with the language but also with the task itself. Pedagogic tasks generate participation and engagement which in turn create opportunities for meaningful language use and language development.

Experimental methods ignore none or partial engagement because they may be against the research questions as the research questions try to find patterns of language learning whereas conversational analysis picture out all sorts of language behavior since they can better show the reality of class. Following the patterns of engagement from none or partial engagement to elaborate engagement shows how learners transform from lower mental functions to higher mental functions through the mediation occurring in conversational interaction.

Differentiating the potential of each task types in creating a medium for language engagement on the part of participants is a very simplistic view and this view masks the potential of each task type in engaging students at ideational level.

To answer the second research question which is whether four task types of the study are different in terms of the mount of engagement produced in each by participants as a result of task performance, a quantitative analysis of the amount of engagement across four task types was conducted and the results show that other things being equal including the proficiency level of the learners, complexity and difficulty levels of the tasks, tasks have different potential in promoting engagement. It is apparent from Table 3 that text reconstruction with the potential and quality index of 133 is the most engaging task and the translation task with the potential index of 62 is the least engaging task. The jigsaw task stands at the 
second rank after translation task in terms of potential in task engagement (110) and dictogloss task is the least potential task in engaging learners after translation task.

Similar to the analysis of task engagement in L1 and L2 done by Lee (2011), closed tasks such as text reconstruction engage learners more than the open end tasks do (jigsaw task, dictogloss). This suggests that besides considering LREs as indicators of learners' engagement with the language which satisfies the criteria (task utility, task naturalness and essentiality) for a task to be considered as an effective task, task engagement should also be considered as an equally important criterion.

\section{Significance}

"Task engagement can be found in the discourse when EFL learners display through either private or social speech their own structuring of the task, and move from mere compliance with the task itself to actual engagement with it" (Platt \& Brook, 2002, p. 373).

There is a long lasting debate in among materials developers about authentic materials. Some researchers believe that it is important that classroom materials are derived from authentic tasks that represent real life. Some others believe that as far as the learning processes that the tasks create are authentic, the tasks are called authentic because these processes prime real life language processing. In other words, authenticity of process is more important than authenticity of product. On the basis of the findings of this research, one probably can associate language engagement with situational authenticity and task engagement with interactional authenticity.

Language engagement and situational authenticity are related to how the learning tasks can create opportunities to use real world language including the segmental and suprasegmental features. Situational authenticity is similar to the authenticity of product and task engagement is similar to interactional authenticity. Task engagement shows how participants are engaged with the tasks from the beginning phases to the end. The evaluation related to task engagement can establish how interactional authenticity can be established as students perform the tasks.

The other issue is ensuring the authenticity of assessment tasks. When defining language tasks, teachers should ensure resemblance of tasks used for the purpose of assessment to everyday language task (Platt \& Brooks, 2002; Weideman, 2006). But, there is also another interpretation of the notion of authenticity which is in line with the findings of this research. So, authenticity is not only a matter of the genuineness of text but also the task itself. That is, the subjective engagement by learners makes the task authentic as it awakens their interest and understanding of its relevance (Weideman, 2006).

\section{Limitation}

This study is limited on a number of grounds. First, task attainment might be affected by various cognitive and affective differences in individuals. Prior controlling for individual 
differences is absent from this research which might affect the learner performance and in turn patterns and amount of task engagement. The other limitation was related to the general propensity of Iranian students towards text-based materials which may affect the way they interact with the task-based materials. Besides, if videotaping was used as an instrument for data collection, a better tacking of behavioral level of engagement could be achieved. Task engagement and individual regulation of the tasks in educational setting are potentially interesting for further research.

\section{Conclusion}

Focus on quantitative and frequency based approach towards what best indicates language learning has been dominant for over decades. But, this approach masks very important aspect of language learning which is more qualitative in nature. In this approach the driving force for learning is internal. Students' engagement with the task as they try to accomplish it is a better indicator of whether transformation in mind occurred and in turn if learning is achieved or not. Students' establishing their own joint ownership of the task helps them to create intersubjectivity which is the aim of all educational programs.

\section{Appendix 1}

\section{Task evaluation questionnaire}

1. To what extent is the goal or goals of the task obvious a) to you b) to your students?

2. Is the task appropriate to the learners' proficiency level?

3. To what extent does the task reflect a real-world or pedagogic rational? Is this appropriate?

4. Is the task likely to be interesting and motivating to the students?

5. Is there an information gap or problem which might promote a negotiation of meaning?

6. Are the activities designed in a way which will allow learners to communicate and cooperate with others?

7. To what extent are learners encouraged to negotiate meaning?

8. Is the task at the appropriate level of difficulty for students?

9. If not, is there any way in which the task might be modified in order to make it either easier or more challenging?

10. Is the task realistic in terms of the resources and teacher-expertise it demands?

\section{Appendix 2}

Task types

\section{Dictogloss}

\subsection{Instructions}

Try to reconstruct the text you are going to listen to with the help of your partner. You must reproduce the original text as faithfully as possible and in a grammatically accurate form. The text will be read twice at normal speed. The first time you listen to the text try to understand the meaning and do not write anything down. The second time you may take notes, writing down either key words or expressions that will help to 
reconstruct the text. Working together you will have to write a final version that is as correct as possible grammatically speaking. Revise carefully what you have written attempting to correct anything that doesn't look right.

\subsection{Input}

There are many countries in the world which are experiencing a variety of problems. Poverty, for example is bad conditions in which people are unable to have their basic needs. Poor people do not have the necessary resources and capacity to have basic needs like food, shelter, health and education. They live under difficult conditions which do not help them to develop their human potential. The other social issue is unemployment. Unemployment and poverty can be harmful for social relations. They can destroy harmony and unity of the family and they can create a feeling of dependence on others. Such effects stop the development of responsibility and self-dependence. Similarly important issue is gender discrimination. Women and men are equally important for the growth and development of individual and social lives. Unfortunately men are thought to have major roles in the society. This discrimination can be seen in work places by giving highly prestigious jobs and higher salary to men. The other important issue is divorce. Much of society has accepted divorce as the solution for a bad marriage. Children of divorce experience psychological harm, health problems, depression and loss of motivation for future life. Crime is one of major social problems presently. Criminal acts of violence may arise within families, within friends or within the whole society. Crime has an impact on the quality of life of the people in society including human injury, destruction, and dehumanization. Banishing criminals to prisons have also become the ground for future violence. Addiction is also one of the important social issues. It can be the cause or the effect of the problems we talked about. This not only affects the people whom it directly touches but its effect spread along the society in the form of various diseases like HIV or criminal acts.

\section{Text reconstruction}

\subsection{Instructions}

Try to reconstruct the text with the help of your partner. You will have to add the words that are missing so that the text is meaningful. Linkers (i.e. prepositions, conjunctions ... etc) have been omitted. Verb endings and articles have also been eliminated. Some words are written in an incorrect form. Discuss with your partner the most accurate way of completing the text and provide the missing words and correct form of the incorrectly written words. You can also make changes if you consider them necessary. You may wish to add some words to connect the different sentences to improve cohesion. Write a grammatically correct final version of the text.

\subsection{Input}

There are many country in the world ........ are experiencing a various of problems. Poverty, for example is bad conditions in.......... people is unable to look after their basic needs. Poor people does not have the necessity resources and capacity to have basic needs like food, shelter, healthy and education. They live under difficulty conditions ........ do not help them to develop their human potential. ......... Social issue is unemployment. Unemployment ........ poverty can be harmful for social relations and they can destroy harmony and unity of the family and they can create a feeling of dependence on others. Such effects stopped the development of responsible and self-dependence. Similarly important issue is gender 
discrimination. Women and men are equal important for .... growth and development of individual and social lives. Unfortunate, men are thought to have major roles in the society. This discrimination seen in work places by giving high prestigious jobs and higher salary to men. ........important issue is divorce. Much of society has accept divorce as the solution for a bad marriage. Children of divorce ........... psychological harm, health problems, depression and loss of motivation for future life. Crime..... one of major social problems presently. Criminal acts of violence may arise within families, within friends or within the whole society. Crime have an ....... on the quality of life of the people in society including human injury, destruction, and dehumanization. Banishing criminals to prisons have also become the ground for future violence. Addiction is ....... one of the importance social issues. It can be the cause or the effect of the problems we talked about. This does not only affect the people ........ it directly touches but its effect spread along the society in the form of variety..... diseases like HIV or criminal acts.

\section{Translation}

\subsection{Instruction}

Read the following passage and try to provide the English equivalent with the help of your partner. Write a grammatically correct English version of the text.

\subsection{Input}

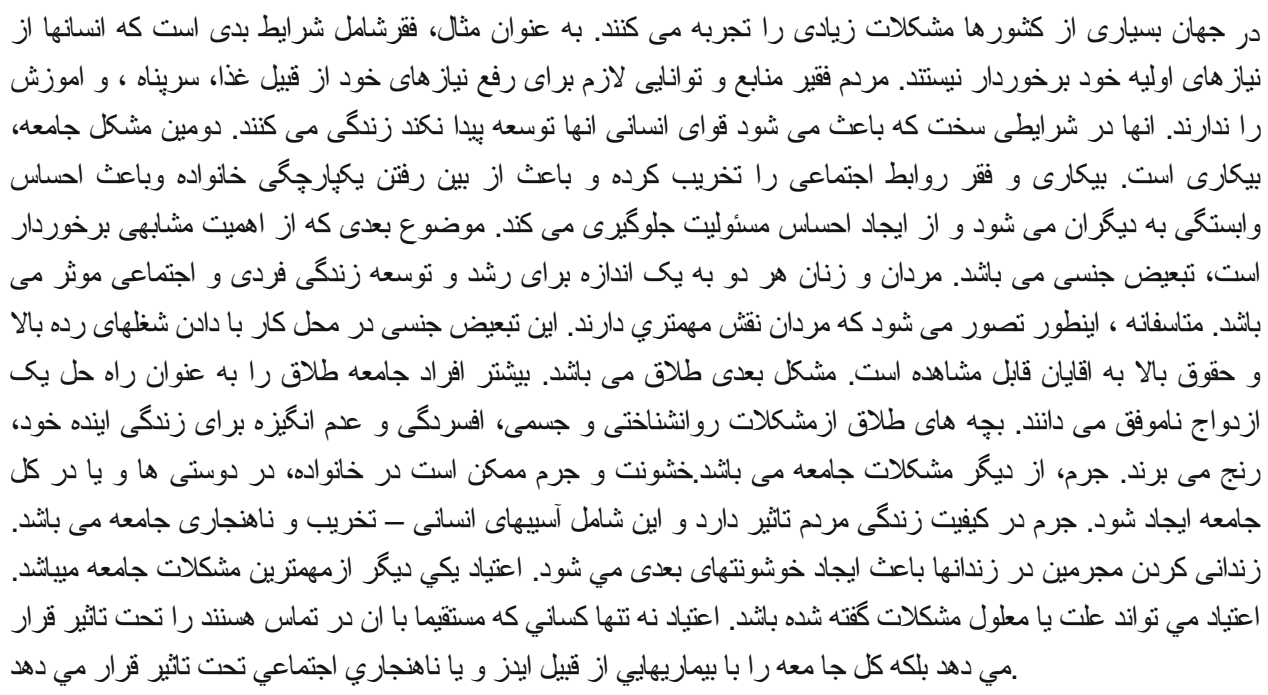

\section{Jigsaw}

\subsection{Instruction}

Try to convey to your partner in English the meaning of the pictures you are holding. Study them carefully so that you know exactly what they mean. One of you will have pictures 1, 3 and 5; and the other, pictures 2, 4 and 6. You cannot look at each other's pictures. Beginning with picture number 1 you will have to convey the information contained in your respective pictures (in order). Once the information is complete, you should write the information in a coherent and grammatically correct paragraph. Please, revise your text carefully. 


\subsection{Visual stimuli}
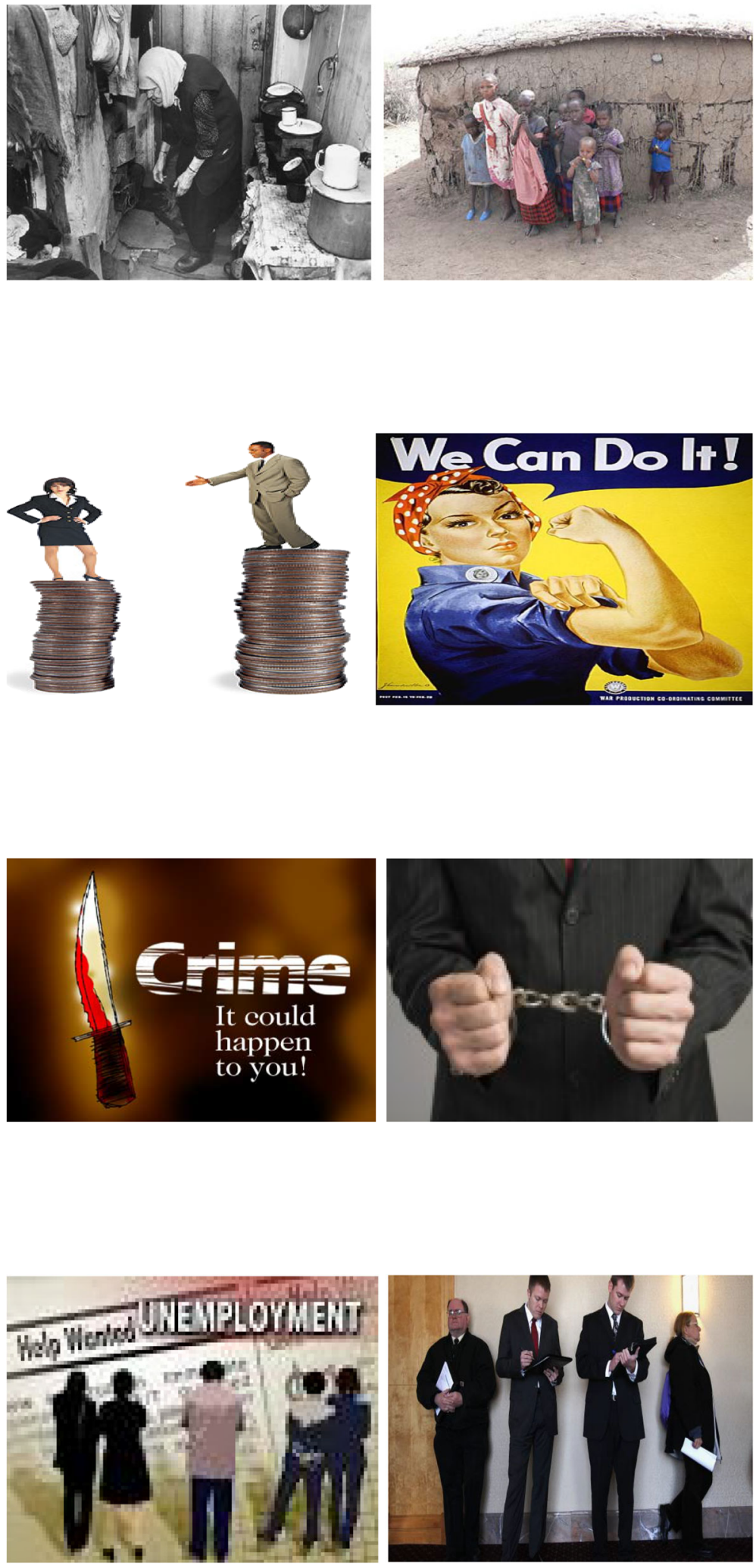

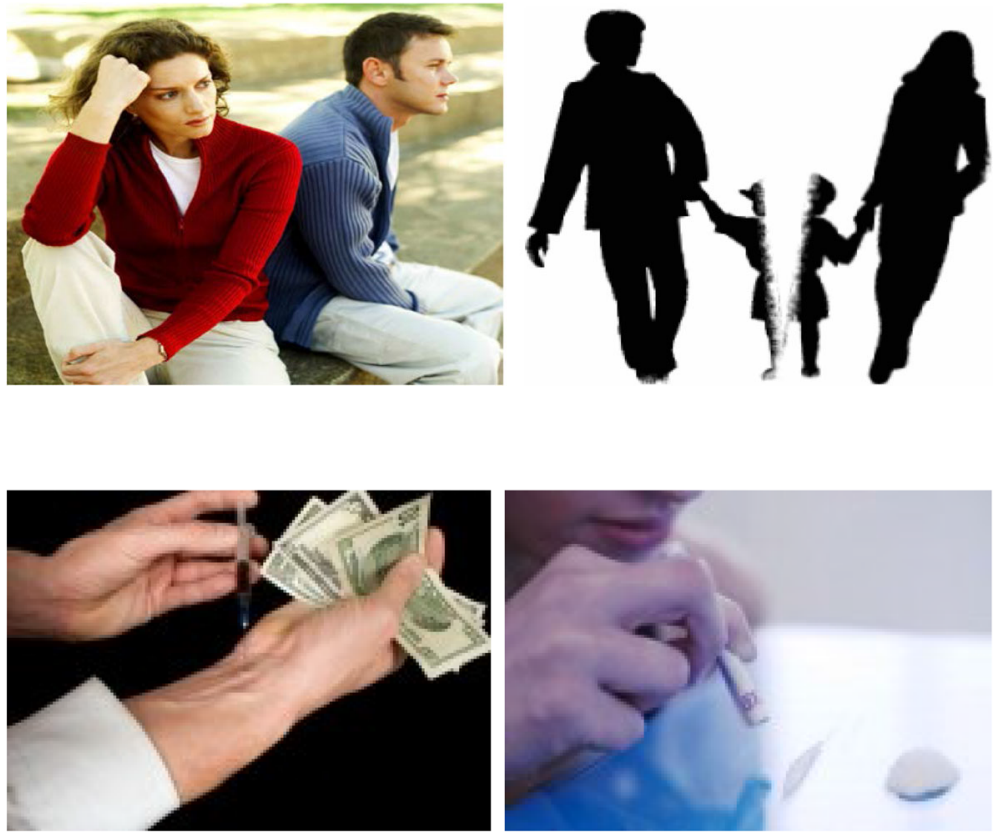

\section{Appendix 3}

Sample transcription and coding protocol and template

\begin{tabular}{|c|c|c|c|c|c|}
\hline Engagement & Abbreviation & $\begin{array}{l}\text { Coding } \\
\text { (pre/ela: } \\
\text { V, P, F) }\end{array}$ & $\begin{array}{l}\text { Justification (why it is } \\
\text { considered as pre/ela: } \\
\mathrm{V}, \mathrm{P}, \mathrm{F} \text { ) }\end{array}$ & Episode & $\begin{array}{l}\text { Timing of } \\
\text { occurrence }\end{array}$ \\
\hline $\begin{array}{l}\text { Recourse to native } \\
\text { language to solve } \\
\text { communication } \\
\text { problems }\end{array}$ & L1 & PreN & $\begin{array}{l}\text { Their early recourse to } \\
\mathrm{L} 1 \text { was fully because } \\
\text { their lack of } \\
\text { knowledge and no } \\
\text { tendency to spend } \\
\text { thoughts on it }\end{array}$ & $\begin{array}{l}\text { S1: children of divorce } \\
\text { became depressed } \\
\text { S2: "Chi" (Meaning } \\
\text { "what") } \\
\text { S1: become } \\
\text { S2: are depressed }\end{array}$ & $\begin{array}{l}\text { At the beginning } \\
\text { phases, time; the } \\
2^{\prime} \text { of the } \\
\text { conversation }\end{array}$ \\
\hline $\begin{array}{l}\text { Negotiation } \\
\text { of form }\end{array}$ & Grammar & Pre/v & $\begin{array}{l}\text { There were a lot of } \\
\text { language related } \\
\text { episodes but as they } \\
\text { moved to the end of } \\
\text { the task there was the } \\
\text { absence of language } \\
\text { related epodes. } \\
\text { Rather, there was } \\
\text { more engagement at } \\
\text { the level of discourse. }\end{array}$ & $\begin{array}{l}\text { S1: there were related } \\
\text { to each other. Aren't } \\
\text { they? } \\
\text { S2: addiction and } \\
\text { crime. Yes } \\
\text { S1: addiction and } \\
\text { crime can cause pour } \\
\text { families } \\
\text { S2: can cause harm } \\
\text { effects on poor } \\
\text { families }\end{array}$ & $\begin{array}{l}\text { Mostly at the } \\
\text { beginning of the } \\
\text { task }\end{array}$ \\
\hline $\begin{array}{l}\text { Expressing } \\
\text { personal view }\end{array}$ & $\begin{array}{l}\text { Personal } \\
\text { ideals }\end{array}$ & $\mathrm{Ela} / \mathrm{v}$ & $\begin{array}{l}\text { There was a case } \\
\text { of elaborate } \\
\text { engagement at the } \\
\text { end of the task since } \\
\text { participants provided } \\
\text { more personal } \\
\text { attitudes. }\end{array}$ & $\begin{array}{l}\text { S1: If he lose his job } \\
\text { S2: and salary } \\
\text { S1: yes I think they } \\
\text { have varieties of } \\
\text { problems including } \\
\text { - }\end{array}$ & $\begin{array}{l}\text { Close to the end } \\
\text { of the task }\end{array}$ \\
\hline $\begin{array}{l}\text { Hesitations and } \\
\text { laughs }\end{array}$ & Pauses & Pre/P & $\begin{array}{l}\text { Long pauses and } \\
\text { hesitations and laughs }\end{array}$ & $\begin{array}{l}\text { S1: it talks about } \\
\text { some countries }\end{array}$ & $\begin{array}{l}\text { At the beginning } \\
\text { of the tasks }\end{array}$ \\
\hline
\end{tabular}


Sample transcription and coding protocol and template (Continued)

\begin{tabular}{|c|c|c|c|c|c|}
\hline & & & $\begin{array}{l}\text { at the beginning of } \\
\text { task performance } \\
\text { mark lack of task } \\
\text { engagement. }\end{array}$ & $\begin{array}{l}\text { S2: many countries } \\
\text { S1: (long pauses) } \\
\text { S2: (laughs and } \\
\text { looking at the } \\
\text { teacher) }\end{array}$ & \\
\hline Intonation cues & $\begin{array}{l}\text { Rising } \\
\text { intonation }\end{array}$ & $\mathrm{Ela} / \mathrm{P}$ & $\begin{array}{l}\text { Rising intonation } \\
\text { which functioned as a } \\
\text { sign to show interest } \\
\text { to continue }\end{array}$ & $\begin{array}{l}\text { S1: the next (rising } \\
\text { intonation which } \\
\text { functions as an } \\
\text { interest to continue) } \\
\text { S2: the next .... } \\
\text { S1: the nest one } \\
\text { S2: the nest social } \\
\text { issue } \\
\text { S1: we use social } \\
\text { issues a lot } \\
\text { S2: ok social problem }\end{array}$ & $\begin{array}{l}\text { Close to the end } \\
\text { of the task }\end{array}$ \\
\hline $\begin{array}{l}\text { Gestures showing } \\
\text { no engagement }\end{array}$ & & Pre/F & $\begin{array}{l}\text { The case of lack of } \\
\text { engagement can be } \\
\text { seen on the part of } \\
\text { the participants by } \\
\text { exhibiting gestures } \\
\text { that show uncertainty } \\
\text { in what have been } \\
\text { said and no further } \\
\text { questioning or } \\
\text { clarification requests. }\end{array}$ & $\begin{array}{l}\text { S1: one social issue is } \\
\text { unemployment } \\
\text { S2: rising eyebrows } \\
\text { (showing he is not } \\
\text { sure about the } \\
\text { partners' answer) } \\
\text { S1:(no more } \\
\text { elaboration) } \\
\text { S2: (no elaboration } \\
\text { request) }\end{array}$ & $\begin{array}{l}\text { Mostly at the } \\
\text { beginning of the } \\
\text { task }\end{array}$ \\
\hline
\end{tabular}

Pre pre-engagement, Ela elaborate engagement; $V$, verbal, $P$ paralinguistic, $F$ Functional

\section{Abbreviations}

EFL: English as a Foreign Language; EL: English Language; LREs: Language related episodes

\section{Funding}

This study is a self-funded research.

\section{Availability of data and materials}

All datasets on which the conclusions of the manuscript rely are presented in the main paper and supporting files.

\section{Competing interests}

The author declares that she has no competing interests.

Received: 22 September 2016 Accepted: 1 February 2017

Published online: 13 March 2017

\section{References}

Aldosari, A. (2008). The Influence of Proficiency Levels, Task Types, and Social Relationships on Pair Interactions: An EFL Context. Unpublished doctoral dissertation. University of Melbourne, School of Languages and Linguistics.

Amirkhiz, S. Y. Y., Bakar, K. A., Samad, A. A., Baki, R., \& Mahmoudi, L. (2013). EFL/ESL Learners' Language Related Episodes (LREs) during Performing Collaborative Writing Tasks. Journal of Language Teaching and Research, 4(3), 473-479.

Ansarin, A. A., \& Mohamadi, Z. (2013a). Language Engagement at the Level of Syntax: Assessing Metatalk and Task Types in SLA. International Journal of Applied Linguistics and English Literature, 2(4), 142-154.

Ansarin, A. A., \& Mohamadi, Z. (2013b). Language Engagement in Task-Based Interaction: Focus on Intonation. The Iranian EFL Journal, 12(2), 152.

Caulfield, J. (2010). Applying graduate student perceptions of task engagement to enhance learning conditions. International Journal for the Scholarship of Teaching and Learning, 4(1), 8.

Csikszentmihalyi, M. (1997). Finding flow: The psychology of engagement with everyday life: Basic Books.

De la Colina, A. A., \& Mayo, M.P. (2007). Attention to form across collaborative tasks by low-proficiency learners in an EFL setting. In M.P. Garcia Mayo (Ed.), Investigating tasks in formal language learning (pp. 91-116). London, UK: Multilingual Matters.

Dembovskaya, S. B. (2009). Task-based instruction: The effect of motivational and cognitive pre-tasks on second language oral French production. Theses and Dissertations, 231.

Dörnyei, Z., \& Kormos, J. (2000). The role of individual and social variables in oral task performance. Language Teaching Research, 4(3), 275-300.

Ellis, R. (2003). Task-based language learning and teaching. Oxford: Oxford University Press.

Foster, P. (1998). A classroom perspective on the negotiation of meaning. Applied Linguistics, 19(1), 1-23.

Geldenhuys, C. M. (2011). Task-based course design for campus communication in ISIXHOSA. Stellenbosch: University of Stellenbosch. 
Hamedani, S. (2013). The relationship between self-efficacy and self-regulation in vocabulary acquisition of Iranian EFL learners. Journal of Academic and Applied Studies, 3(1), 20-31.

Kamil, M. L., Borman, G. D., Dole, J., Kral, C. C., Salinger, T., \& Torgesen, J. (2008). Improving Adolescent Literacy: Effective Classroom and Intervention Practices. IES Practice Guide. NCEE 2008-4027. National Center for Education Evaluation and Regional Assistance.

Lee, H-G. (2011). Exploring a model of ESL motivation and engagement. (Unpublished doctoral dissertation). Washington State University, Pullman.

Lee, H. G. (2012). ESL learners' motivation and task engagement in technology enhanced language learning contexts. Unpublished doctoral dissertation. Washington State University Research Exchange.

Lee, L. (2016). Autonomous learning through task-based instruction in fully online language courses. Language Learning \& Technology, 20(2), 81-97

Lutz, S. L., Guthrie, J. T., \& Davis, M. H. (2006). Scaffolding for engagement in elementary school reading instruction. The Journal of Educational Research, 100(1), 3-20.

Ma, J. H. (2009). Autonomy, competence, and relatedness in L2 learners' task motivation: A self-determination theory perspective. Unpublished doctoral dissertation. University of Hawai'i at Manoa.

Maad, M. R. B. (2012). Interaction effect of task demands and individual differences on L2 learners' perception of task difficulty and motivation. The Journal of Language Teaching and Learning, 2(1), 01-14

Meltzer, J., \& Hamann, E. T. (2005). Meeting the Literacy Development Needs of Adolescent English Language Learners Through Content-Area Learning-PART TWO: Focus on Classroom Teaching and Learning Strategies.

Mozgalina, A. (2015). More or less choice? The influence of choice on task motivation and task engagement. System, 49, 120-132.

Nakahama, Y., Tyler, A., \& Lier, L. (2001). Negotiation of meaning in conversational and information gap activities: A comparative discourse analysis. TESOL Quarterly, 35(3), 377-405.

Nunan, D. (1989). Designing tasks for the communicative classroom: Cambridge: Cambridge University Press.

Oliver, R., \& Mackey, A. (2003). Interactional context and feedback in child ESL classrooms. The Modern Language Journal, 87(4), 519-533.

Paris, S. G., \& Paris, A. H. (2001). Classroom applications of research on self-regulated learning. Educational Psychologist, 36(2), 89-101.

Pellettieri, J. (2010). Online chat in the foreign language classroom: From research to pedagogy. Mextesol Journal, 34(1), 41-57.

Platt, E., \& Brooks, F. B. (2002). Task engagement: A turning point in foreign language development. Language Learning, $52(2), 365-400$

Polio, C., \& Gass, S. M. (1998). The role of interaction in native speaker comprehension of nonnative speaker speech. The Modern Language Journal, 82(3), 308-319.

Russell, J., Mackay, T. \& Jane, G. (2003) Messages from MYRAD: Improving the Middle Years of Schooling . Melbourne, Australia: Incorporated Association of Registered Teachers of Victoria.

Sandholtz, J. H., Ringstaff, C., \& Dwyer, D. C. (1994). Student engagement: Views from technology-rich classrooms. Document téléaccessible à l'adresse. https://pdfs.semanticscholar.org/5e1b/ 3dabf5e2b43b43bdc46711600112910e6035.pdf.

Storch, N. (1998). A classroom-based study: Insights from a collaborative text reconstruction task. ELT Journal, 52(4), 291-300.

Storch, N. (2005). Collaborative writing: Product, process, and students' reflections. Journal of Second Language Writing, $14(3), 153-173$.

Storch, N. (2008). Metatalk in a pair work activity: Level of engagement and implications for language development. Language Awareness, 17(2), 95-114.

Storch, N., \& Wigglesworth, G. (2007). Writing tasks: The effects of collaboration. Investigating tasks in formal language learning, 157-177.

Weideman, A. (2006). Assessing academic literacy: A task-based approach

Wigfield, A., \& Guthrie, J. T. (2000). Engagement and motivation in reading. Handbook of Reading Research, 3, 403-422.

\section{Submit your manuscript to a SpringerOpen ${ }^{\circ}$ journal and benefit from:}

- Convenient online submission

- Rigorous peer review

- Immediate publication on acceptance

- Open access: articles freely available online

- High visibility within the field

- Retaining the copyright to your article

Submit your next manuscript at $>$ springeropen.com 